\title{
Parameter properties of granite moonstone under unloading condition
}

\author{
Yinghui LV ${ }^{1, a}$, Yao XU1,b \\ ${ }^{1}$ School of Civil Engineering and Architecture, University of Jinan, China \\ acea_lvyh@ujn.edu.cn, bea_xuy@ujn.edu.cn
}

Keywords: unloading, properties, mechanical parameters, strength.

Abstract: In order to get parameter properties of rock mass, a series of representative unloading tests are carried on hard granite moonstone for that it is indispensable to get mechanical parameters and strength parameters for numerical simulation. In the unloading tests, the stress path of decreasing confining pressure along with increasing axial pressure is adopted to be similar to the evacuation of rock mass at depth. The results of tests show as follows:

(1) As the cracks development in rock mass, the mechanical parameters and strength parameters is not constant.

(2) In the process of unloading, the Poisson's ration would be risen gradually and the deformation modulus would be decreased little by little.

(3) Two strength parameters, the internal cohesion and the internal friction angel are both reduced greatly, compared to that in loading tests.

\section{Introduction}

With the development of computer technology, large-scale numerical simulations are widely used for engineering designs in geotechnical engineering. It is indispensable to get parameter properties of rock for numerical simulation, and so far, most research results are limited to that under load conditions. However, it is also confirmed that parameter properties of rock under unloading condition differ from those under load condition. When research results under load conditions are applied to unloading constructions, errors will occur ${ }^{[1]}$. Therefore, it is very significant for simulation analysis to study parameter properties of rock under unloading condition.

As thus, a series of representative unloading tests are carried on hard granite moonstones, which come from the underground workshop excavation zone in Dagangshan hydropower station in western China. And it is hoped that the research can be bring reasonable suggestion to engineering design on unload.

\section{Unloading test plan}

To ensure correct control of test and accurate measurement of parameters, MTS815.3 Program-controlled Rock Stiff Test Machine, which is made in U.S.A with two program-controlled channels (axial pressure and confining pressure) and with four types of control modes (load, stress, strain and displacement), is applied in this test. In the test, all rock specimens are done as cylinders with height/diameter 2:1, and the initial stress conditions on all specimens are also expressed in Tab.1. The unloading test process is undertaken in the following four stages:

Stage 1: Gradually apply and increase axial pressure $\sigma_{1}$ and confining pressure $\sigma_{3}$ to the destined value $\sigma_{0}$.

Stage 2: Then steady $\sigma_{3}$ and at the same time, steadily increase $\sigma_{1}$ to a initial stress condition before the specimen is destroyed.

Stage 3: Then slowly increase $\sigma_{1}$ and gradually reduce $\sigma_{3}$ at the same time.

Stage 4: At the end, analyze the tests after the specimen is destroyed. 
Table.1. initial stress condition of specimens

\begin{tabular}{|c|c|c|c|c|c|}
\hline \multirow{2}{*}{ Test specimen } & $\mathrm{U} 3-1$ & $\mathrm{U} 4-1$ & $\mathrm{U} 6-1$ & $\mathrm{U} 8-1$ & $\mathrm{U} 10-1$ \\
\cline { 2 - 6 } & $\mathrm{U} 3-2$ & $\mathrm{U} 4-2$ & $\mathrm{U} 6-2$ & $\mathrm{U} 8-2$ & $\mathrm{U} 10-2$ \\
\hline $\begin{array}{c}\text { Initial confining } \\
\text { pressure } \sigma_{0} / \mathrm{MPa}\end{array}$ & 20 & $\mathrm{U} 4-3$ & $\mathrm{U} 6-3$ & $\mathrm{U} 8-3$ & $\mathrm{U} 10-3$ \\
\hline $\begin{array}{c}\text { Initial } a x i a l \\
\text { pressure } \sigma_{1} / \mathrm{MPa}\end{array}$ & 300 & 30 & 60 & 80 & 100 \\
\hline
\end{tabular}

\section{Analysis of mechanical parameters}

E-? 3 curves of and ?-13 curves at different initial confining pressure $\sigma_{0}$ are present from Fig. 1 to Fig.10, and we can obtain such results as follows by those curves:

A. The deformation modulus and the Poisson's ration should not be seen as a constant for that there is an obvious variation in the stage of unloading.

B. With the unloading process, the Poisson's ration increase distinctly and the deformation modulus decrease gradually.

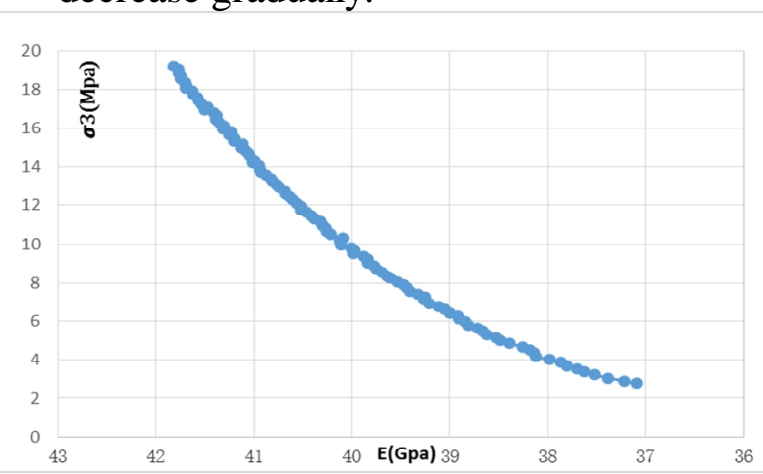

Fig.1, E- 33 curve at $\sigma_{0}=20 \mathrm{MP} \overline{\mathrm{c}}$

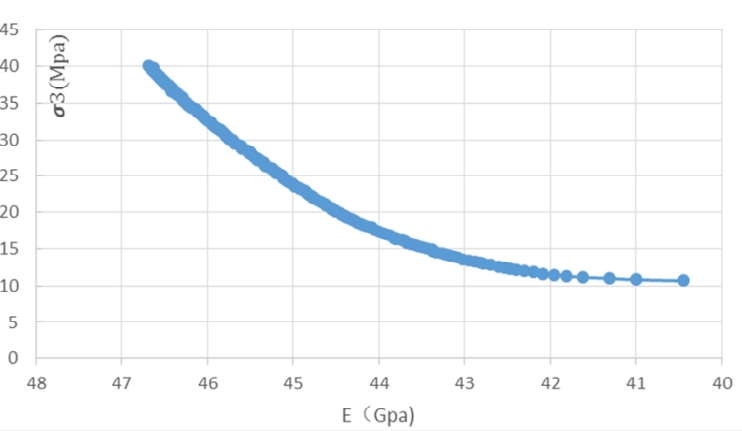

Fig.3, E-? 3 curve at $\sigma_{0}=40 \mathrm{MP}$;

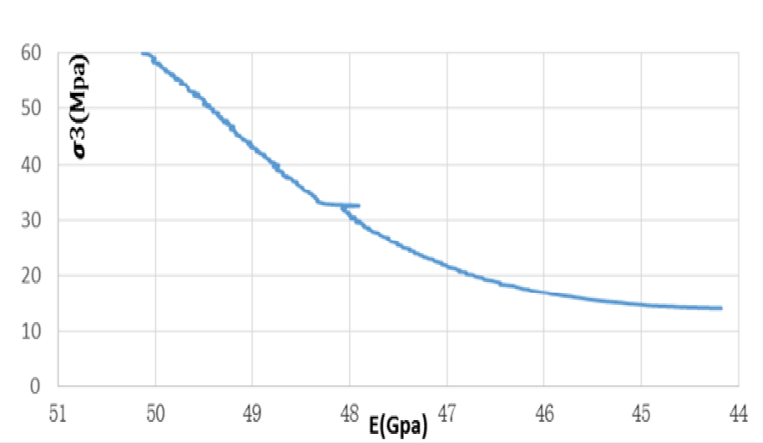

Fig.5, E- ? 3 curve at $\sigma_{0}=60 \mathrm{MP}$ i

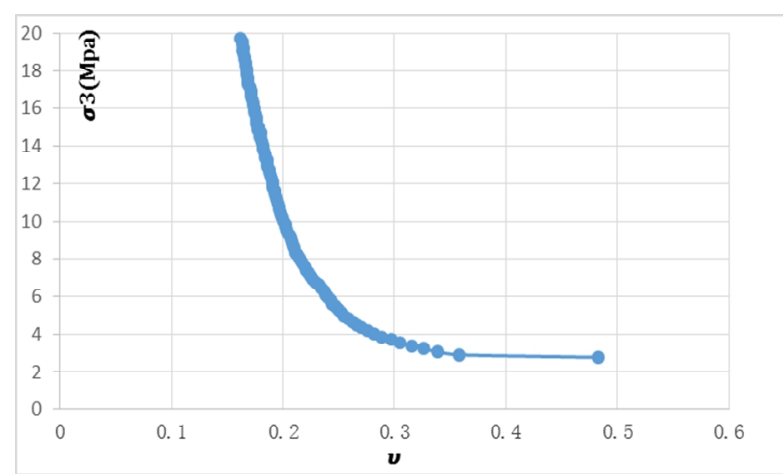

Fig.2, ?-2 3 curve at $\sigma_{0}=20 \mathrm{MP} \bar{c}$

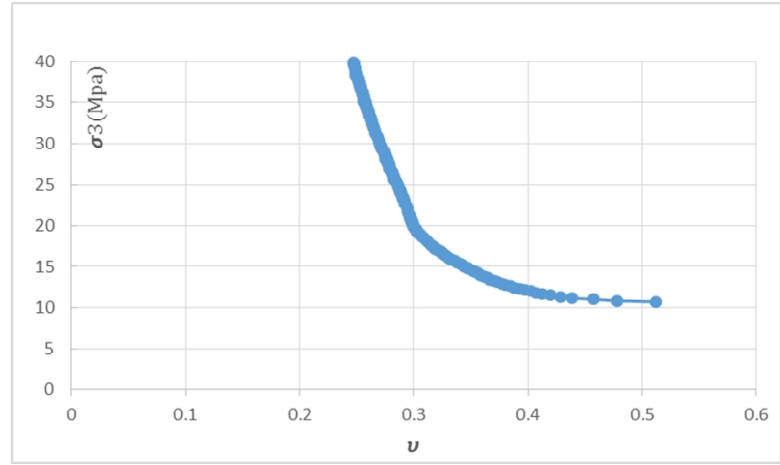

Fig.4, ?-? 3 curve at $\sigma_{0}=40 \mathrm{MP}$ i

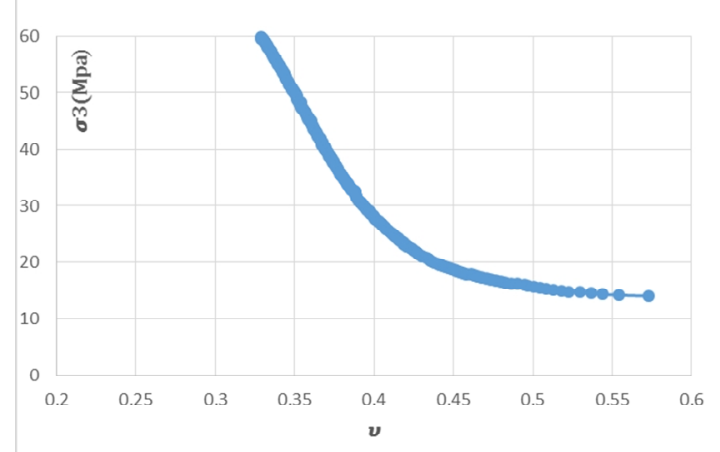

Fig.6, ? - ? 3 curve at $\sigma_{0}=60 \mathrm{MP} \bar{c}$ 


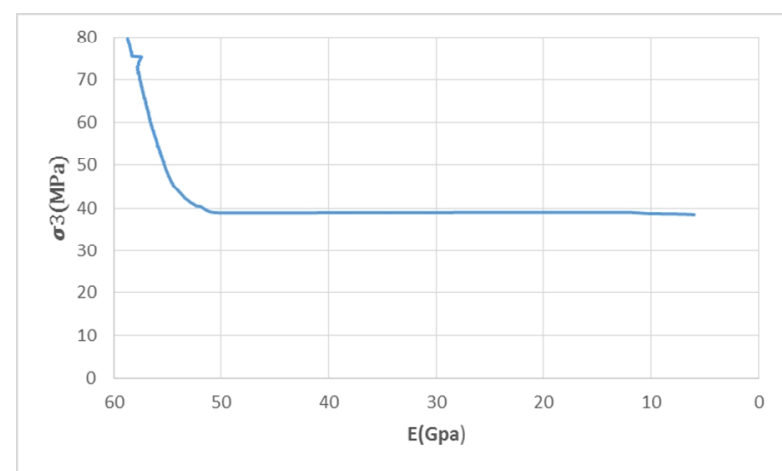

Fig.7, E-? 3 curve at $\sigma_{0}=80 \mathrm{MP}$ i

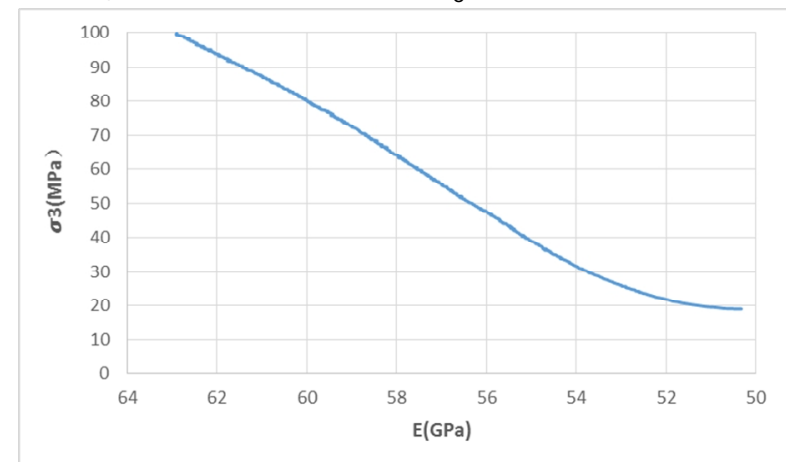

Fig.9, E- ? 3 curve at $\sigma_{0}=100 \mathrm{MP}$;

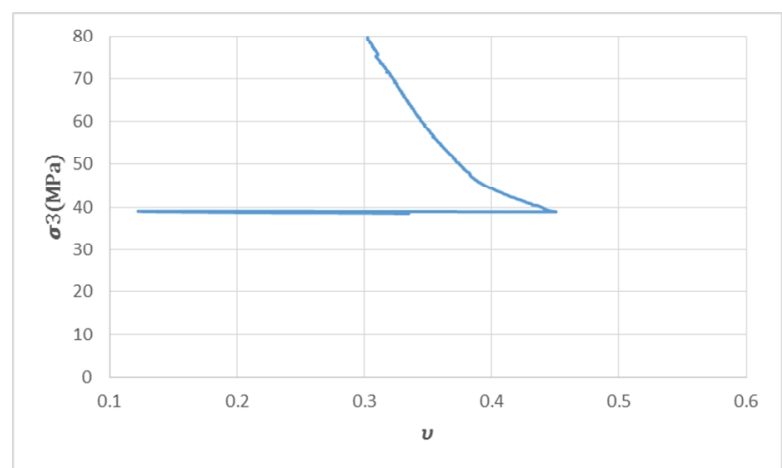

Fig.8, ?-? 3 curve at $\sigma_{0}=80 \mathrm{MP}$ i

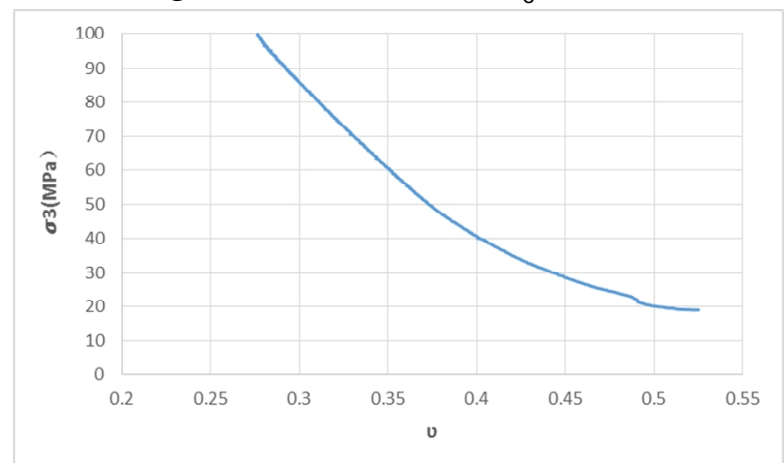

Fig.10, ?-0 3 curve at $\sigma_{0}=100 \mathrm{MP}$;

\section{Strength test and analysis of strength parameters}

In order to analyze properties of strength parameters, structure surface shear strength test are carried on these unloaded rock samples. In strength tests, the normal force is firstly increased gradually to booked value, and then the shear force is increased at one speed till to the failure. Fig.11 expresses the curves of shear force and shear displacement.

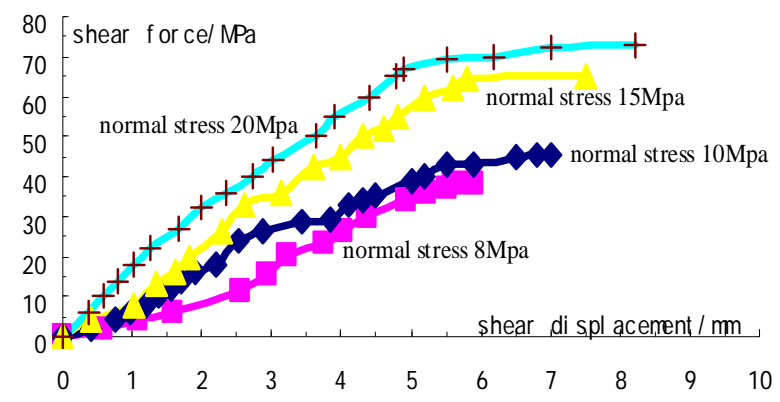

Fig.11 the curves of shear force and shear displacement.

Based on the shear tests, linear Mohr-Coulomb criterion is used to describe the rock failures, and in geotechnical engineering, the Mohr-Coulomb criterion is the most commonly accepted as factures criterion. Fig. 12 shows the fitting curve. In fig.12, the intercept at vertical axis equals to the internal cohesion $C$, and the tangent angel of curve expresses the internal friction angel $\varphi$. So the following two equals can be get easily:

$$
\begin{aligned}
& \mathrm{c}=13.89 \mathrm{MP} \overline{\mathrm{c}} \\
& \varphi=72.56^{\circ}
\end{aligned}
$$

Fig.13 describes the Mohr-Coulomb strength envelop of rock samples in the state of load. And from Fig.5, the two strength indexes can be get as follows:

$$
\begin{aligned}
& c=29.53 \mathrm{MP} \\
& \varphi=51.89^{\circ}
\end{aligned}
$$




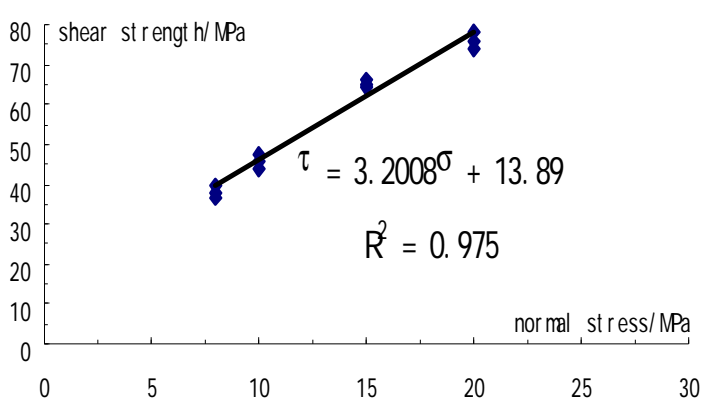

Fig. 12 the fitting curve about Mohr-Coulomb

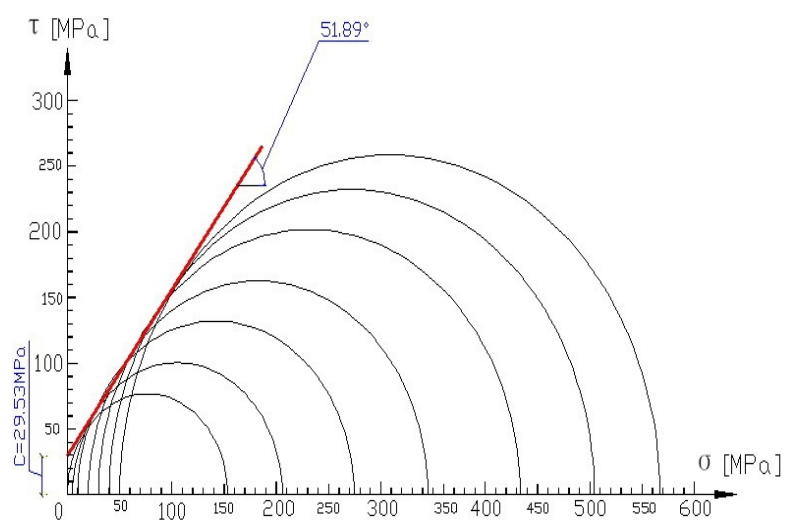

Fig.13 the Mohr-Coulomb strength envelope

By the comparison from equalities (1) to (4), it can be concluded that because of unloading, the internal cohesion $C$ is reduced greatly and the internal friction angel $\varphi$ is increased.

\section{Conclusions}

A series of representative unloading tests and strength tests have been performed on granite moonstones, the following conclusions can be reached:

A. Under unloading condition, with the appearance of cracks, the internal friction angel is risen and the internal cohesion is decreased.

B. Under unloading condition, hard granites behave brittle failure and the linear Mohr-coulomb criterion can well describe the failure characteristics.

C. In the stage of unloading, the Poisson's ration rise and the deformation modulus can not be as constants for that the two indexes have both variation trend.

\section{Acknowledgements}

The research presented in the paper is supported by National Natural Science Foundation of China (NO.10902118) and the Natural Science Foundation of University of Jinan (NO.XBS1041)

\section{References}

[1] H.Q.XIE, CH. HE. STUDY ON THE UNLOADING CHARACTERISTICS OF A ROCK MASS USING THE TRIAXIAL TEST AND DAMAGE MECHANICS[J]. Int. J. Rock mech. Min. sci. 41(2004), 207-214.

[2] Adel M. Al-Ajmi, Robert W. Zimmermana, Relation between the Mogi and the Coulomb failure criteria[J]. International Journal of Rock Mechanics \& Mining Sciences, 42 (2005), 431-439.

[3] SHEN Junhui, WANG Lansheng, WANG Qinghail. Deformation and fracture features of unload rock mass[J]. Chinese Journal of Rock Mechanics and Engineering, 2003, 22(12): 2028-2031.

[4] Haimson BC, Chang C. A new true triaxial cell for testing mechanical properties of rock, and its use to determine rock strength and deformability of Westerly granite. Int $\mathbf{J}$ Rock MechMin Sci, 37(2000): 285-296.

[5]LIU Quansheng HU Yunhua, LIU Bin. Progressive damage constitutive models of granite based on experimental results[J]. Rock and Soil Mechanics, 2009, 30(2):289-296

[6] Chang C, Haimson B. True triaxial strength and deformability of the German Continental deep drilling program (KTB) deep hole amphibolite. J Geophys Res, 105(2000), 9013-18999. 